\title{
Proposta de um modelo geométrico e computacional para simulação de fluência estática em concretos asfálticos
}

\author{
Marcone de Oliveira Junior', Márcio Muniz de Farias², Igor Augusto Rodrigues ${ }^{3}$ \\ 1Universidade de Brasília, marcone@outlook.com \\ 2Universidade de Brasília, mmuniz94@gmail.com \\ 3Universidade de Brasília, igor_ar@hotmail.com
}

\section{Recebido:}

04 de outubro de 2018

Aceito para publicação:

31 de janeiro de 2019

Publicado:

31 de dezembro de 2019

Editor de área:

Jorge Barbosa Soares

\section{Palavras-chaves:}

Elementos Finitos,

Mistura asfáltica,

Fluência estática,

Agregados graúdos.

\section{Keywords:}

Finite Elements,

Asphalt mixture,

Static creep,

Coarse aggregates.

DOI:10.14295/transportes.v27i4.1859

OPEN

ACcESS

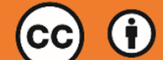

\begin{abstract}
RESUMO
Neste trabalho, os autores buscam representar, de forma simplificada, o esqueleto sólido correspondente aos agregados graúdos componentes de uma mistura asfáltica, a fim de incorporá-los na modelagem numérica do material via Método dos Elementos Finitos. Para isso, são analisadas a granulometria e a forma dos agregados graúdos e consideradas essas características na modelagem geométrica do problema, fazendo uso de modelos com empacotamentos randômicos gerados tridimensionalmente. Do ponto de vista constitutivo os agregados graúdos são considerados sólidos elásticos lineares e a Matriz de Agregados Finos (MAF) é considerado um material contínuo viscoelástico. A fim de validar o modelo, são comparados resultados experimentais de ensaios de fluência estática com ensaios virtuais simulados utilizando a técnica descrita, apresentando resultados bastante satisfatórios.
\end{abstract}

\begin{abstract}
In this paper, the authors aim to represent, in a simplified way, the solid skeleton relative to the coarse aggregates in a hot asphalt mixture. The objective is to incorporate the coarse aggregates in the numerical modeling of the material using the Finite Element Method. The grain size distribution and shape of the coarse aggregates are analyzed and considered in the geometric model, using a three-dimensional random packing technique. From the constitutive point of view, the coarse aggregates are simulated as linear elastic solids, while the Matrix of Fine Aggregates is considered a viscoelastic continuum material. To validate the model, experimental results of a creep and recovery test are compared to the results of virtual tests simulated using the proposed technique, attaining excellent agreement.
\end{abstract}

\section{INTRODUÇÃO}

O Concreto Betuminoso Usinado a Quente (CBUQ) é uma mistura de Agregados Graúdos (G), Agregados Miúdos (M), Agregados de Enchimento ou Fíler (F) e Ligante Asfáltico (CAP), contendo ainda vazios (Var) no seu interior preenchidos por ar. A Matriz de Agregados Finos (MAF), considerada uma matriz viscoelástica, corresponde ao ligante asfáltico juntamente com os agregados miúdos e fíler ( $\mathrm{CAP}+\mathrm{M}+\mathrm{F})$. Outras denominações também têm sido utilizadas com pequenas variações nos limites de corte do que seja a parte fina. Encontram-se na literatura os termos mástique e argamassa asfáltica (García, 2017), esta última correspondendo a uma mistura fina semelhante a uma Areia Asfalto Usinada a Quente. 0 termo MAF será adotado no contexto deste trabalho. 
Pode-se ainda, segundo García (2017), dividir a composição da mistura asfáltica em diferentes fases, como a seguir: (1) a primeira composta por agregados graúdos, miúdos e fíler mineral, a segunda composta pelo ligante asfáltico, e a terceira referente aos vazios; (2) agregados graúdos e miúdos compondo a primeira fase, a segunda composta por fíler mineral e ligante asfáltico (mástique), e a terceira referente aos vazios; (3) a primeira fase composta pelos agregados graúdos, a segunda composta por agregados finos, fíler e ligante asfáltico, e a terceira referente aos vazios.

Adotam-se, para fins de simulação numérica, duas fases: a primeira, correspondente aos agregados graúdos, e a segunda, composta pela mistura entre os agregados finos, fíler mineral e ligante asfáltico. A primeira fase será referida como Esqueleto Sólido Graúdo (ESG) e a segunda por Matriz de Agregados Finos (MAF). Salienta-se, no entanto, que a MAF será caracterizada como uma matriz contínua de modo a incluir a presença de seus vazios implicitamente nas suas propriedades constitutivas. Na estrutura aqui concebida para um CBUQ, a MAF preenche os vazios e aglutina os agregados graúdos, os quais são responsáveis por conferir, em grande parte, rigidez à mistura, devido às suas propriedades físicas, distribuição granulométrica e forma.

0 comportamento de misturas asfálticas é genericamente visco-elasto-plástico, devido à sua heterogeneidade e aos materiais específicos de sua composição. Fatores como taxa, tempo e magnitude do carregamento, além da temperatura, podem afetar o comportamento do material, conferindo diferentes graus de importância para as parcelas elástica, plástica ou viscosa na representação do mesmo (Huang, 1993). De acordo com a separação de fases adotada neste artigo (ESG e MAF), o esqueleto sólido, quando isolado, tem uma resposta tipicamente elasto-plástica (Farmer, 1983), enquanto que matriz de agregados finos é geralmente assumida como tendo uma resposta viscoelástica. Tanto os componentes plásticos, quanto os viscosos contribuem para o acúmulo de deformações permanentes, sendo que as primeiras (bem como as elásticas) ocorrem em fase temporal com o carregamento, enquanto que a parte viscosa é defasada. Cabe salientar, entretanto, que para níveis de deformações considerados nos ensaios replicados, com aplicação de carga compressiva de $100 \mathrm{kPa}$, os agregados comportam-se apenas de forma elástica (Farmer, 1983).

0 método mais simples para a caracterização de materiais viscoelásticos, típicos em pavimentação rodoviária, é a obtenção de uma curva de fluência sob carga estática constante em laboratório. Esta curva é geralmente representada matematicamente por uma associação em série ou em paralelo de elementos simples (molas e amortecedores) que definem um modelo reológico, sendo mais utilizado o modelo de Maxwell Generalizado (Huang, 1993). A curva do módulo de flexibilidade à fluência (creep compliance, em inglês) ao longo do tempo para este modelo pode ser expressa por uma série de Prony, que é um somatório de unidades elementares, obtidos em intervalos de tempo pré-definidos (Hu et al., 2015). Esta curva se inter-relaciona com a curva do módulo de relaxação, no domínio do tempo, por meio de uma integral de convolução, considerando-se carregamento uniaxial, sem efeitos de envelhecimento e condições isotérmicas (Denby, 1975; Park e Kim, 1999). Definida a série de Prony de flexibilidade, é possível obter os módulos de relaxação do modelo de Maxwell generalizado, de acordo com Kim (2009). São extraídos, assim, os coeficientes que permitem definir o comportamento viscoelástico do material.

A capacidade de carga e a resistência total à deformação de um concreto asfáltico advêm, basicamente, do intertravamento e do atrito de contato entre agregados, principalmente os 
graúdos, ou seja, da estrutura do esqueleto sólido (Dai, 2011; Dai e You, 2007; Witczak et al., 2002; Rocco e Elices, 2009; Zelelew, 2008). A MAF responde pela cimentação para manter as partículas de agregado unidas (Zelelew, 2008), conferindo resistência coesiva e características viscosas à mistura. É importante, então, conhecer as propriedades de cada fase constituinte (ESG e MAF) a fim de obter um modelo coerente que possa retratar o comportamento da mistura. As proporções e distribuições dos materiais também devem ser tomados em consideração, visto que determinam o tipo de comportamento (elástico, viscoso ou plástico) que deve se sobressair. Para o ESG, foco do presente trabalho, é importante representar a granulometria e a forma das partículas de maneira mais próxima à realidade.

A forma das partículas tem influência direta na resistência ao cisalhamento das misturas asfálticas, sendo que partículas irregulares ou de forma angular tendem a apresentar melhor intertravamento entre os grãos compactados (Castillo et al., 2017; Zhou et al., 2017). Bessa et al. (2014) e Pazos et al. (2015) também estudaram a influência da forma e da angularidade de partículas de agregados no comportamento de misturas asfálticas, e concluíram que o melhor cenário, em termos de performance mecânica, seria aquele em que se utiliza de partículas mais angulares, e com maior textura superficial. Segundo esses autores, materiais graúdos considerados ideais para pavimentação são, em geral, mais cúbicos.

Existem diversas maneiras de se caracterizar a forma e as dimensões de materiais particulados. Partículas tridimensionais podem assumir formatos com irregularidades que, na maioria das vezes, são difíceis de serem reproduzidas geometricamente. Uma maneira simplificada de se caracterizar a forma deste tipo de material é por meio de razões de aspecto, que são medidas adimensionais que têm o objetivo de relacionar as dimensões características de uma partícula (Al-Rousan et al., 2007; Morfa et al., 2018). Três coeficientes muito utilizados se referem à lamelaridade, planicidade e angularidade. Para a aplicação específica na análise de forma de agregados, estes valores representam, respectivamente, o quão alongado, plano e irregular é o formato do agregado (Farias et al., 2018). Na análise de um meio particulado, estes três valores devem ser calculados para cada partícula e tratados estatisticamente a fim de se definir um valor que represente o conjunto total de partículas.

Simulações numéricas necessitam de uma configuração de partículas inicial realista. Ao longo do tempo, diferentes métodos de empacotamento foram propostos, sendo eles classificados em métodos dinâmicos e construtivos (Bagi, 2005). Métodos dinâmicos são baseados em simulações de Elementos Discretos, com análise prévia do movimento das partículas. Já os construtivos geram partículas em sua posição final, em contato com duas ou três outras partículas, no caso de pacotes densos em 2D e 3D, respectivamente. Valera et al. (2015) apresentam um método de empacotamento construtivo de frente de avanço que compreende partículas geralmente circundando as outras, e determina todas as posições possíveis nas quais as novas partículas podem ser localizadas.

Xu et al. (2010) desenvolveram um algoritmo de geração de agregados tridimensionais e de empacotamento aplicável para modelagem de misturas asfálticas com grande presença de agregados graúdos. No algoritmo, poliedros de formas arbitrárias são usados para modelar os agregados, de maneira que o efeito da forma dos mesmos no comportamento do concreto asfáltico possa ser considerado. Entretanto, utiliza-se de ferramentas implícitas no programa ANSYS, que demandam muito tempo computacional e são difíceis de aplicar para um grande número de partículas. 
Aragão et al. (2015) apresentaram uma metodologia de análise microestrutural para quantificar características volumétricas fundamentais de amostras virtuais de misturas asfálticas, como granulometria, fração de área e orientação das partículas agregadas. Além disso, foi desenvolvido um gerador de microestruturas que usa imagens de agregados reais e características volumétricas para criar amostras virtuais bidimensionais (2D) de misturas asfálticas.

O objetivo do presente artigo é obter características geométricas essenciais dos agregados e gerar um modelo simplificado do empacotamento do esqueleto sólido para uma modelagem mais realista do comportamento de misturas asfálticas tipo CBUQ sujeitas a ensaios de fluência estática. 0 pacote de partículas virtuais é importado para o programa de Elementos Finitos ABAQUS, o qual discretiza os agregados graúdos e o espaço vazio entre eles, que será preenchido totalmente pela matriz de agregados finos.

\section{MATERIAIS E MÉTODOS}

Trata-se de um Concreto Betuminoso Usinado a Quente (CBUQ), por ser o tipo de revestimento asfáltico mais utilizado no Brasil. A composição do concreto asfáltico se enquadra na Faixa C, conforme a norma ES 031 (DNIT, 2006). Reitera-se aqui a intenção de estudar apenas a fração granulométrica correspondente aos agregados graúdos (ESG), eliminando a parte miúda, que é estudada de forma incorporada à matriz asfáltica. 0 material pétreo será um calcário dolomítico e a argamassa asfáltica foi produzida com o cimento asfáltico de petróleo CAP 50/70, ambos típicos de obras no Distrito Federal.

\subsection{Caracterização dos agregados graúdos}

Agregados graúdos aqui são definidos como o material pétreo retido na peneira \#4 (4,75 mm). O material foi caracterizado a fim de prover dados necessários para sua inclusão na simulação numérica de um concreto asfáltico. Para isso, objetivou-se construir uma composição granulométrica que atenda à Faixa C, normatizada pelo DNIT 031/2006, e cujos centro e limites inferior e superior são mostrados pela Figura 1.

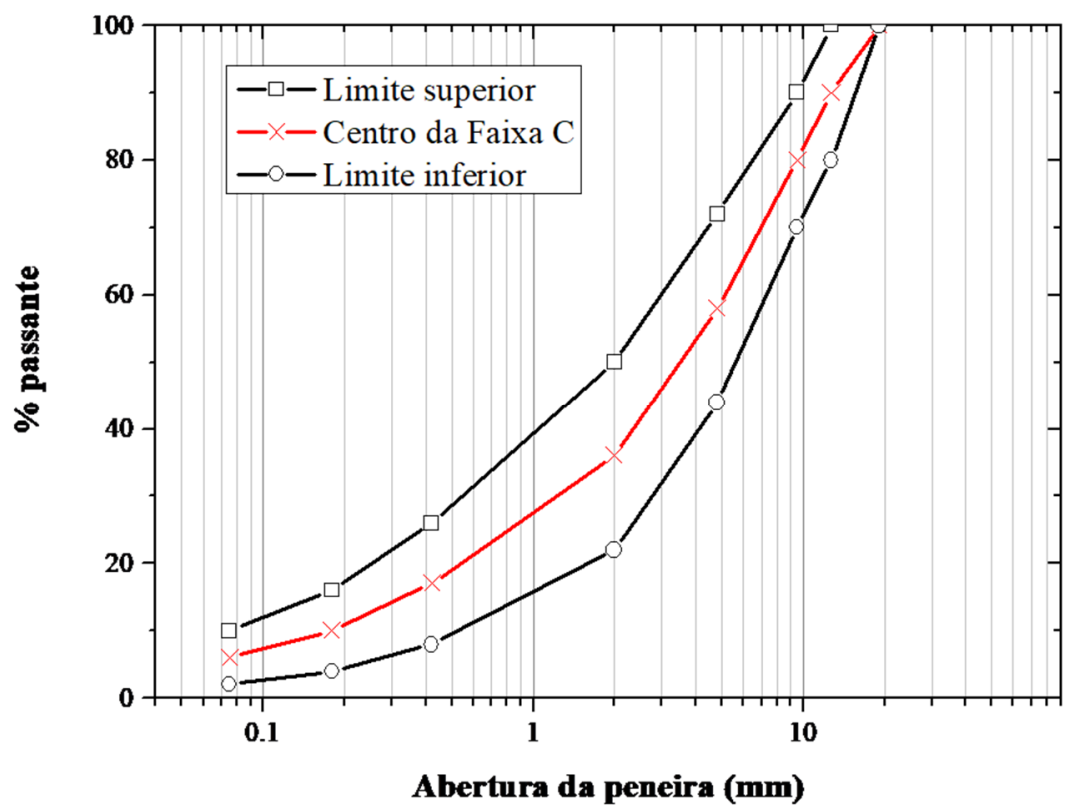

Figura 1. Composição Granulométrica da Faixa C do DNIT 
Para avaliar a forma do agregado graúdo, a ABNT NBR 7809 (1983) define o índice de forma como uma média da relação entre comprimento e espessura dos grãos do agregado, ponderada pela quantidade de grãos de cada fração granulométrica que compõe a mistura (Faixa C). Atendendo às recomendações da norma, foram feitas as medidas de comprimento, largura e espessura de 200 grãos de agregado graúdo, em quantidades proporcionais às frações granulométricas encontradas no peneiramento da amostra.

Ao final do processo de medição, são obtidos, utilizando um paquímetro, como ilustrado pela Figura 2, o comprimento $(a)$, a largura $(b)$ e a espessura $(c)$ dos agregados, conforme a norma ABNT NBR 6954 MB 894 (1989).

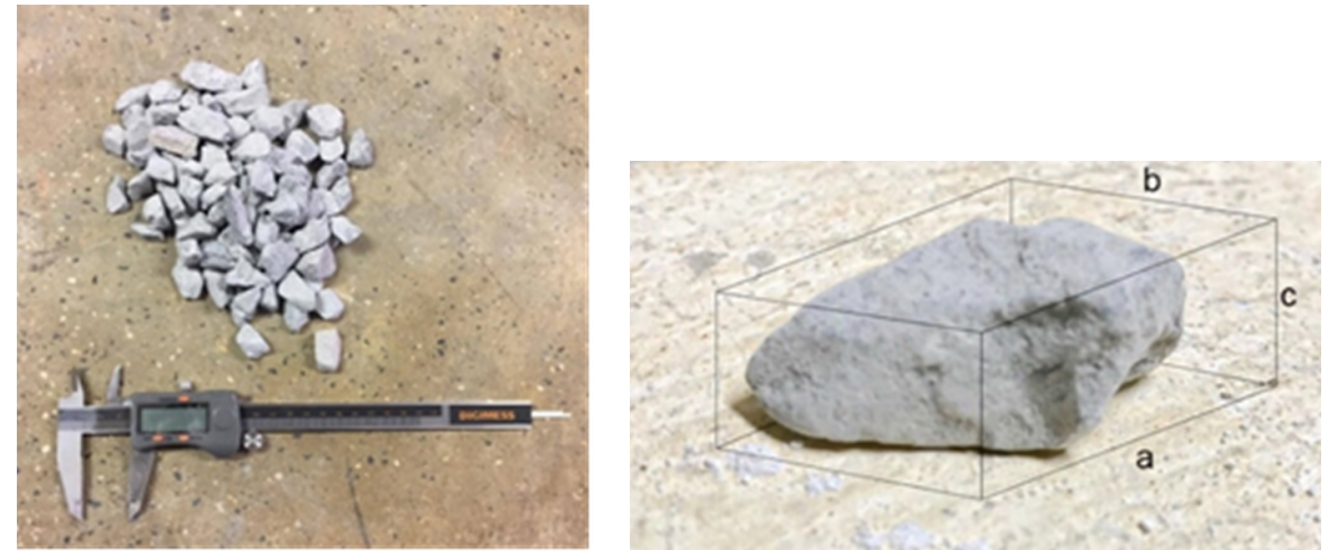

Figura 2. Análise de forma com paquímetro.

Esse método trata a avaliação da forma de maneira mais aprofundada que somente pela análise do Índice de Forma. Para a classificação da forma, segundo essa norma, são determinadas e relacionadas entre si as razões $b / a$ e $c / b$. A Tabela 1 resume a classificação das partículas.

Tabela 1 - Classificação da forma das partículas (ABNT NBR 6954 MB 894/1989 - modificado pelo autor).

\begin{tabular}{ll}
\hline Média das relações $\boldsymbol{b} / \boldsymbol{a}$ e $c / \boldsymbol{b}$ & Classificação \\
\hline$b / a>0,5$ e $c / b>0,5$ & Cúbica \\
$b / a<0,5$ e $c / b>0,5$ & Alongada \\
$b / a>0,5$ e $c / b<0,5$ & Lamelar \\
$b / a<0,5$ e $c / b<0,5$ & Alongada-lamelar \\
\hline
\end{tabular}

\subsection{Coleta de dados da AAUQ e do CBUQ}

As misturas asfálticas utilizadas nesse trabalho são compostas por duas fases: esqueleto sólido graúdo (ESG) e Matriz de Agregados Finos (MAF). Os ensaios de fluência estática e recuperação na matriz de agregados finos foram realizados por Rodrigues (2018) e serão utilizados neste trabalho para a modelagem da fase MAF, integrante do modelo completo. Na composição da mesma foi utilizado um ligante asfáltico CAP 50/70 e, no modelo numérico, as especificações e características volumétricas do material adotado no referido trabalho foram seguidas, além do mesmo processo de realização do ensaio.

O ensaio de compressão uniaxial é realizado sob uma temperatura de aproximadamente $25{ }^{\circ} \mathrm{C}$, com aplicação de carga estática uniformemente distribuída de $100 \mathrm{kPa}$ durante $3600 \mathrm{~s}$, com posterior descarregamento por $900 \mathrm{~s}$ para análise do retorno elástico do material. Os deslocamentos verticais do topo do corpo de prova são registrados ao longo do tempo do ensaio, 
permitindo o cálculo das deformações verticais. Ao final do ensaio de fluência estática, é obtida a evolução das deformações uniaxiais do corpo de prova, em função do tempo de aplicação da carga. Pode-se, então, encontrar os valores de flexibilidade à fluência (creep compliance - $D(t)$ ), dividindo-se as deformações uniaxiais pela tensão constante aplicada.

O ensaio de fluência estática com recuperação realizado por Rodrigues (2018) gerou uma curva de deslocamentos uniaxiais ao longo do tempo. Foram realizadas três réplicas do ensaio de fluência estática e, por fim, gerada a curva média, com desvio padrão máximo de 0,0022 mm. Os dados brutos estão apresentados na Figura 3. De posse dos valores de deformação obtidos a partir dos deslocamentos, pode-se gerar uma curva de fluência média, apresentada na Figura 4 , em escala $\log x \log$.

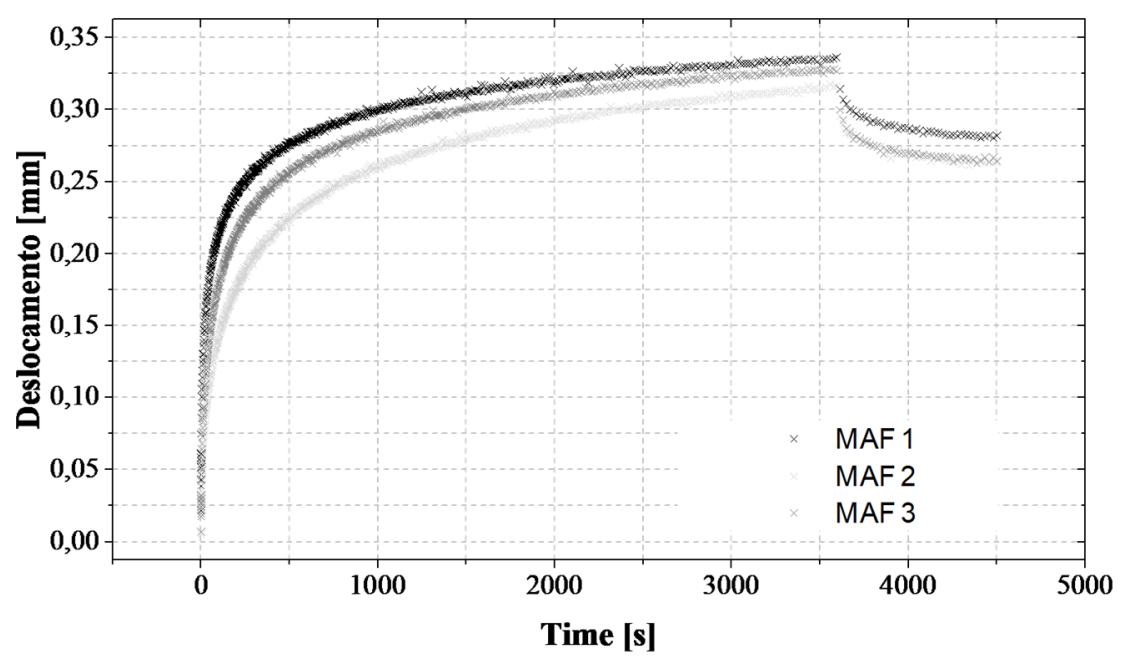

Figura 3. Resultados experimentais obtidos de Rodrigues (2018).

Utilizando-se de uma interconversão baseada na Lei de Potência, apresentada por Park e Kim (1999), obtém-se também a função Relaxação $E(t)$, representada graficamente na Figura 4. De posse dessa função, é possível caracterizar a fase no modelo numérico a partir dos parâmetros retirados da mesma e apresentados na seção de modelagem numérica.

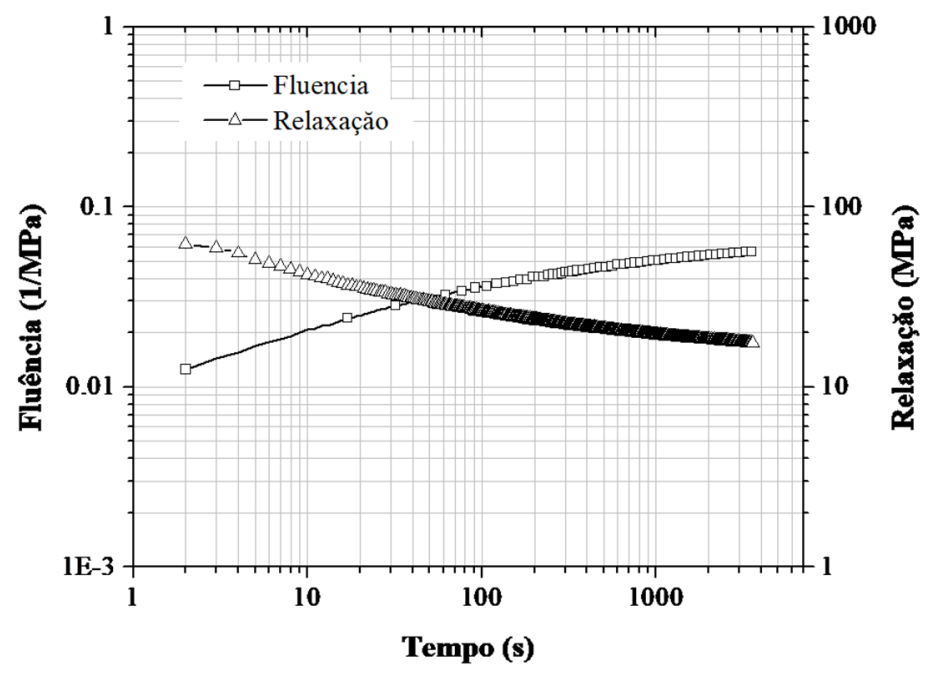

Figura 4. Interconversão entre funções $D(t)$ e $E(t)$ 
Também do trabalho de Rodrigues (2018) foram retirados resultados de parâmetros volumétricos do CBUQ e do ensaio de fluência estática do mesmo. Os parâmetros volumétricos permitem estimar a ocupação volumétrica dos agregados graúdos no modelo, e a curva de deslocamento $\mathrm{x}$ tempo obtida no experimento permite validar o modelo numérico desenvolvido no presente trabalho, ao comparar os resultados. Considerando a mistura com vazios do agregado mineral (VAM) de 13,4\%, conforme os dados experimentais, tem-se uma ocupação de 86,6\% de agregados minerais, da qual 36,4\% destes correspondem aos agregados graúdos. 0 restante compõe os vazios do agregado mineral graúdo VAM-G, correspondente a 63,6\%, o qual será preenchido com a MAF. De posse desse valor, foi calculada a porosidade do pacote de sólidos graúdos como 0,636, parâmetro esse de entrada para o algoritmo de empacotamento de partículas virtuais.

\subsection{Geração de partículas virtuais e empacotamento}

Para a construção do esqueleto sólido graúdo (ESG), foi adotada uma técnica de geração randômica de agregados. Para isso, utilizou-se um algoritmo apresentado por Pérez Morales et al. (2011) e Valera et al. (2015), chamado de "frente de avanço", que produz um empacotamento de partículas aleatório, respeitando parâmetros de entrada definidos pelo usuário. 0 código é abastecido com características necessárias ao empacotamento referentes às dimensões médias da partícula padrão, porosidade e granulometria, seguindo a porção graúda do centro da Faixa C, apresentada na Figura 5. Por fim, o algoritmo cria, como saída, o pacote de partículas.

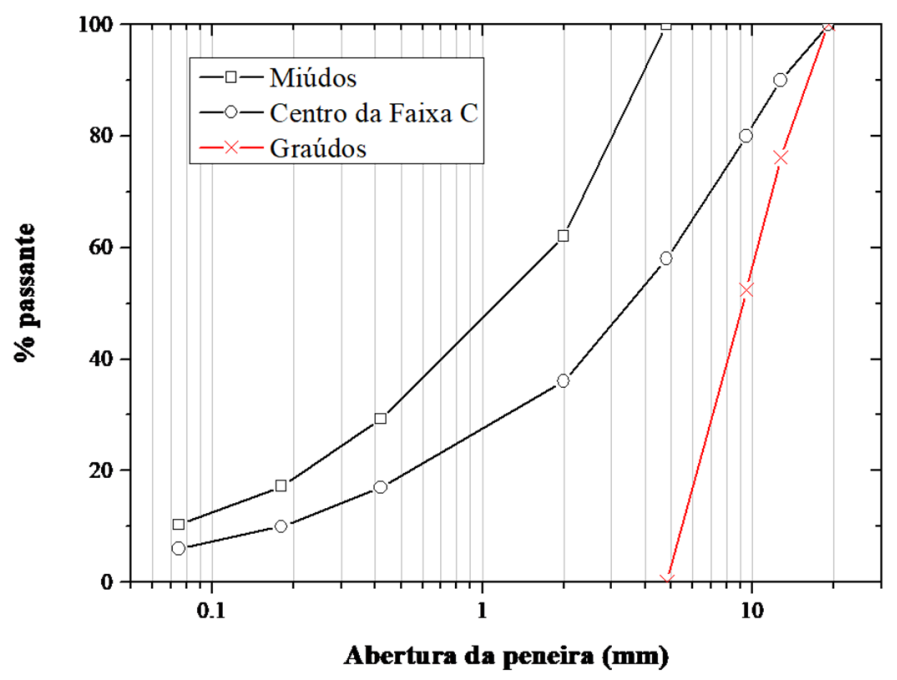

Figura 5. Composição granulométrica da parte graúda do centro da Faixa C

0 arquivo de saída gerado corresponde a uma lista de partículas e as coordenadas de seus vértices. Com o uso de outro algoritmo, essas coordenadas são lidas e interligadas, de forma a construir o conjunto de partículas em um formato compatível com o programa AutoCAD, que permite criar um arquivo no formato ".igs", suportado pelo programa de elementos finitos ABAQUS, com a composição das partículas em três dimensões.

\subsection{Modelagem numérica de corpo de prova de mistura asfáltica}

A composição da mistura é formada pelo esqueleto sólido, ilustrado na Figura 6-a, importado como uma parte da montagem e delimitado por uma região cilíndrica com as dimensões de um 
corpo de prova Marshall (100 mm de diâmetro por $60 \mathrm{~mm}$ de altura). Os grãos que excedem este limite são automaticamente truncados pelo pré-processador. 0 conjunto de grãos forma uma primeira sub-região do domínio e os vazios entre os grãos formam a outra sub-região, a qual será preenchida pela matriz asfáltica, conforme ilustrado na Figura 6-b.
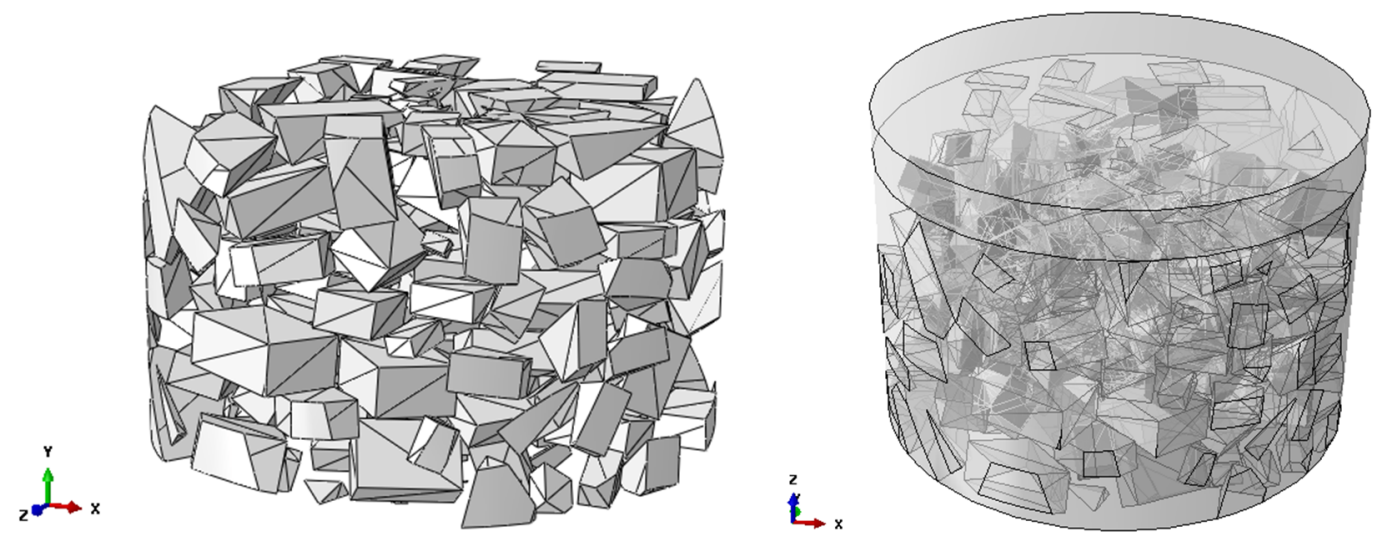

Figura 6. (a) Esqueleto sólido dos agregados inseridos no corpo de prova; (b) Corpo de prova constituído por argamassa asfáltica e agregados graúdos

Ressalta-se que o algoritmo de empacotamento garante que não haja superposição entre as partículas, mas há pontos de contato entre algumas partículas. Os pontos de contato podem se dar em qualquer combinação entre vértices, arestas ou faces. Não foram adotados modelos de contato nem entre os grãos sólidos e nem entre estes e a matriz viscoelástica. Portanto, não há deslocamentos relativos e mantém-se a compatibilidade de deslocamentos entre os diferentes elementos de acordo com a formulação básica do MEF.

Os materiais que compõem a mistura são definidos segundo suas propriedades, de acordo com o modelo constitutivo adotado. Assumiu-se que os grãos dos agregados graúdos (calcário dolomítico) se comportam como materiais elásticos lineares, enquanto a argamassa asfáltica é caracterizada por um modelo viscoelástico, inserido a partir de coeficientes normalizados de uma série de Prony de uma curva de relaxação da mesma obtida experimentalmente. Para os grãos graúdos foram adotadas as seguintes propriedades: módulo de Young E $=60 \mathrm{GPa}$ e coeficiente de Poisson $v=0,25$, valores sugeridos para rochas calcárias, dentro de uma faixa aceitável, por Farmer (1983).

Para a MAF, empregou-se um modelo viscoelástico definido pelos parâmetros constitutivos dependentes da série de Prony da função Relaxação $E(t)$. 0 modelo reológico adotado, do tipo Maxwell Generalizado consiste em 4 unidades viscoelásticas de Maxwell associadas em paralelo a uma unidade puramente elástica. A função, como evidencia Huang (1993), é obtida pela aproximação de uma série de Prony, ou Dirichlet, que resulta em:

$$
E(t)=E_{\infty}+\sum_{i=1}^{n} E_{i}^{-\left(\frac{t}{\rho_{i}}\right)}
$$

sendo: $\mathrm{E}(\mathrm{t})$ o módulo de relaxação, $\mathrm{E}_{\infty}$ o módulo de equilíbrio a tempo infinito, $\mathrm{n}$ o número de termos da série de Prony, e $E_{i}$ e $\rho_{i}$ termos da série de Prony.

Para a representação de um comportamento isotrópico no programa ABAQUS, são necessárias relações entre o módulo cisalhante e volumétrico, de forma análoga a materiais elásticos:

$$
G(t)=\frac{E(t)}{2(1+v)}
$$




$$
K(t)=\frac{E(t)}{3(1-2 v)}
$$

sendo: $G(t)$ o Módulo de cisalhamento no tempo; $K(t)$ o Módulo volumétrico no tempo, e $v$ o coeficiente de Poisson, constante no tempo.

Os valores de módulos volumétricos constituem os parâmetros de entrada para a definição do modelo constitutivo do material viscoelástico, bem como o módulo $E_{\infty}$ correspondente ao módulo de relaxação no tempo infinito, devidamente calibrado a partir de testes prévios para compensar efeitos das simplificações adotadas. Além disso, observou-se que, para a fase de descarregamento, o programa ABAQUS adota o módulo de relaxação a tempo infinito (Eœ desc) como o mesmo do carregamento, o que de fato não acontece nos ensaios realizados, como pode ser observado na Figura 3. Os deslocamentos médios nos 900 segundos iniciais da fase de carregamento foram da ordem de $0,28 \mathrm{~mm}$, enquanto que na fase de descarregamento (entre $3600 \mathrm{e}$ $4500 \mathrm{~s}$ ) apenas foram recuperados $0,05 \mathrm{~mm}$. Na prática, isto significa que os níveis de deformações impostos ao final do carregamento, da ordem de $2700 \mu \varepsilon$, causam danos permanentes à matriz asfáltica fina.

Apesar disto é possível representar adequadamente o comportamento experimental, utilizando-se um modelo viscoelástico com os parâmetros devidamente calibrados para o tempo de ensaio executado. Isto é mostrado na Figura 7, onde estão plotadas a curva experimental média dos ensaios na MAF e a curva teórica obtida com o modelo viscoelástico calibrado (Fig. 7-a). Na Figura 7-b, mostra-se os pares de resultados experimental e teórico, bem como a reta de referência de igualdade. A análise estatística mostra uma forte correlação entre os dados para a fase do carregamento, obtendo-se um coeficiente de Pearson $r=0,99948$. Portanto, o modelo reológico adotado, consegue reproduzir os dados experimentais, na fase de carregamento.

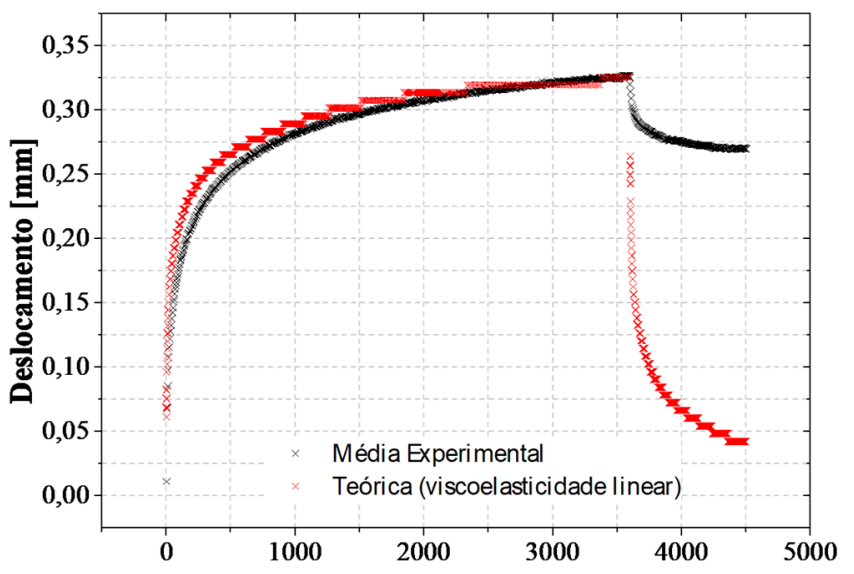

(a)

Time [s]

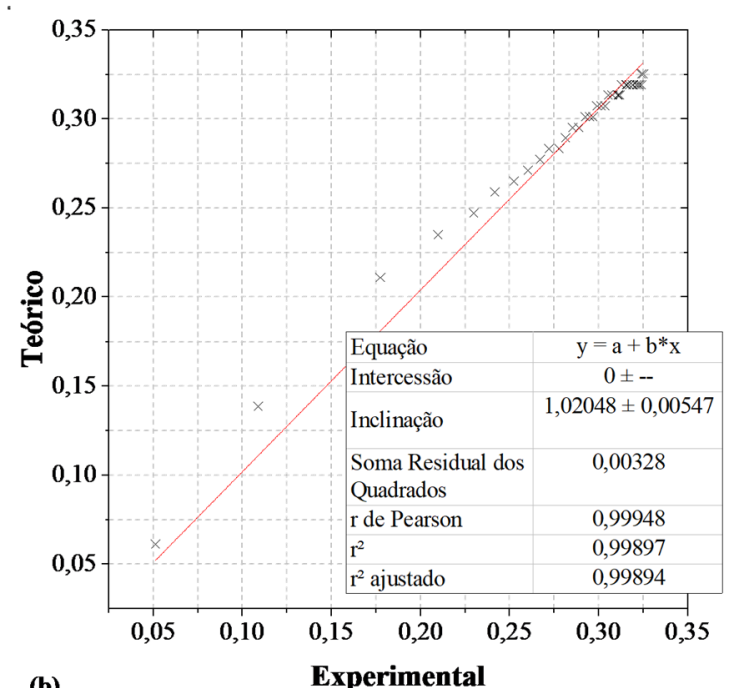

Figura 7. (a) Curvas média experimental e teórica; (b) Correlação entre resultados das duas curvas (para o carregamento)

Não obstante, a aplicação dos mesmos parâmetros para a fase de descarregamento, produziria uma recuperação elástica muito superior à de fato observada. Para contornar este problema, a simulação foi realizada adotando-se módulos diferentes nas duas etapas: (1) acomodamento e carregamento, e (2) descarregamento. A rigor isto significa que foi adotado um modelo pseudo viscoelástico, da mesma forma que se chama de pseudo elástico (não-linear) ao modelo hiperbólico de Duncan e Chang (1970), que adota diferentes módulos de elasticidade 
para as fases de carregamento e descarregamento. Com base nos resultados experimentais, observou-se que o comportamento da curva no descarregamento é muito similar ao carregamento, guardadas apenas as proporções de magnitude. Desta forma percebeu-se que não seria modificar todos os módulos de elasticidade das unidades de Maxwell do modelo reológico, mas apenas o módulo da Young da unidade puramente elástica (mola). Estimou-se, então, a partir dos dados experimentais, um novo módulo Eø para o descarregamento, como um módulo proporcional ao do carregamento, conforme:

$$
E_{\infty \mathrm{desc}}=E_{\infty \mathrm{ccar}} \cdot \frac{\delta_{900}}{\delta_{3600}-\delta_{4500}}
$$

sendo: $E_{\infty}$ desc o módulo de relaxação no tempo infinito da etapa de descarregamento, Eळ car 0 módulo de relaxação no tempo infinito da etapa de carregamento, $\delta 900$ o deslocamento para $\mathrm{t}=900 \mathrm{~s}, \delta_{3600}$ o deslocamento para $\mathrm{t}=3600 \mathrm{~s}$ (fim do carregamento) e $\delta_{4500}$ o deslocamento para $\mathrm{t}=4500 \mathrm{~s}$ (fim do descarregamento).

Com base em testes realizados para determinação do valor de $E_{\infty}$ desc, determinou-se um $E_{\infty}$ desc $=3,2 \cdot E_{\infty}$ car. A simulação do modelo considerando diferentes $E_{\infty}$ em carregamento e descarregamento permitiu uma melhor representação desses estágios realizados no ensaio de fluência estática.

A mistura heterogênea, dividida em duas fases, é submetida a uma carga constante uniformemente distribuída de $100 \mathrm{kPa}$ durante 3600 segundos, com posterior descarregamento por 900 segundos. As cargas foram aplicadas sobre uma placa rígida em contato com o topo do corpo de prova a fim de uniformizar os deslocamentos na face superior. Os deslocamentos na base foram restritos nas três direções, de modo a incluir possíveis efeitos de aderência entre o corpo de prova e a placa, entretanto este não é um detalhe muito relevante para o problema em estudo. Utilizou-se um esquema de integrações explícitas, com passos de tempo controlados pela tolerância de erro de deformações viscoelásticas máxima de 0,01.

A montagem do corpo de prova combina duas sub-regiões: o esqueleto sólido e a matriz de agregados finos, que envolve a primeira. 0 pré-processador do programa ABAQUS gera uma malha a partir destas sub-regiões, respeitando a compatibilidade entre ambas e também as condições de contorno do problema. Para tanto, é preciso gerar uma malha não-estruturada e o elemento finito mais adequado para este tipo de problema é um tetraedro não-linear com 10 pontos nodais (elemento C3D10 do programa ABAQUS). Em média, cada corpo de prova modelado apresenta cerca de 60000 nós e 42000 elementos. Os nós globais foram dispostos distantes em $10 \mathrm{~mm}$ entre si, enquanto os nós locais em $5 \mathrm{~mm}$. 0 estudo de refinamento foi realizado de forma a se obter uma relação satisfatória entre eficiência e custo computacional. As análises foram completadas em cerca de 30 minutos cada, utilizando-se de um hardware composto por um Processador Intel ${ }^{\circledR}$ Core $^{\mathrm{TM}}$ i7-47-90 e 32 GB de memória RAM.

\subsection{Validação do modelo numérico desenvolvido}

A fim de validar o modelo numérico desenvolvido, foram realizadas três simulações, mantendose parâmetros de forma, granulometria, volume de ocupação de agregados no corpo de prova, além dos modelos constitutivos, porém variando as posições e orientações das partículas de forma randômica. Foram registrados os deslocamentos verticais no centro do topo da placa sobre os corpos de prova durante a simulação numérica. A placa rígida acima do CP não se deforma, mas pode girar devido à disposição aleatória dos agregados dentro da amostra. Adotando-se os deslocamentos verticais no centro do topo da placa rígida, tende-se a representar o 
deslocamento médio da superfície. Assim, a curva de progressão de deslocamentos ao longo do tempo de cada corpo de prova é criada e, com a média de três curvas, compara-se os resultados numéricos e experimentais.

Os resultados de ensaios de fluência estática realizados por Rodrigues (2018) no laboratório INFRALAB, sob as mesmas condições ensaiadas, foram utilizados para validar o modelo desenvolvido. A simplificação da representação dos agregados reais no modelo numérico utilizando de uma forma padrão sob uma disposição aleatória permite facilitar a aplicabilidade do método. Dessa forma, é possível, de forma relativamente rápida, replicar o ensaio tantas vezes quantas forem necessárias.

\section{RESULTADOS}

A metodologia apresentada anteriormente foi aplicada aos materiais correspondentes. A seguir são apresentados os resultados encontrados nos ensaios realizados e na simulação numérica.

\subsection{Análise granulométrica}

A Tabela 2 mostra as porcentagens retidas em cada uma das peneiras utilizadas para atender ao centro da Faixa C. Reitera-se que, para a modelagem numérica somente a fração graúda, representada graficamente na Figura 5 já apresentada, foi utilizada como parte constituinte do modelo.

\begin{tabular}{cl} 
Tabela 2 - Peneiramento - Porcentagens passantes na Fa \\
\cline { 2 - 2 } Abertura da peneira [mm] & Porcentagem passante \\
\hline 19,1 & $100 \%$ \\
12,7 & $90 \%$ \\
9,5 & $80 \%$ \\
4,8 & $58 \%$ \\
2,36 & $36 \%$ \\
0,42 & $17 \%$ \\
0,18 & $10 \%$ \\
0,075 & $6 \%$ \\
\hline
\end{tabular}

\subsection{Avaliação da forma}

Foram analisadas as medidas de 200 partículas, possibilitando o cálculo de suas correlações, para determinar a forma das partículas, conforme a ABNT NBR 6954 MB 894 (1989). Os resultados das medidas de comprimento, largura e espessura estão expressos nos histogramas da Figura 8. Foram encontrados valores médios de 22,53 mm, 15,26 mm e 9,46 mm para as medidas, respectivamente. Os desvios padrão das medidas, na ordem exposta, são 5,09 mm, 3,11 mm e $2,73 \mathrm{~mm}$.

De posse desses dados, foram excluídos os outliers, com confiabilidade de 95\%, de forma a rejeitar grãos pouco representativos. Encontraram-se, assim, novos valores médios, apresentados na Tabela 3. A tabela também resume as relações encontradas, que permitem classificar os agregados como cúbicos, em média. Encontrou-se um valor de Índice de Forma de 2,39. 0 valor não é exatamente próximo de 1, que seria o de uma partícula perfeitamente cúbica, porém é aceitável visto que é inferior a 3, valor máximo de referência segundo a ABNT NBR 7809 (2006). 

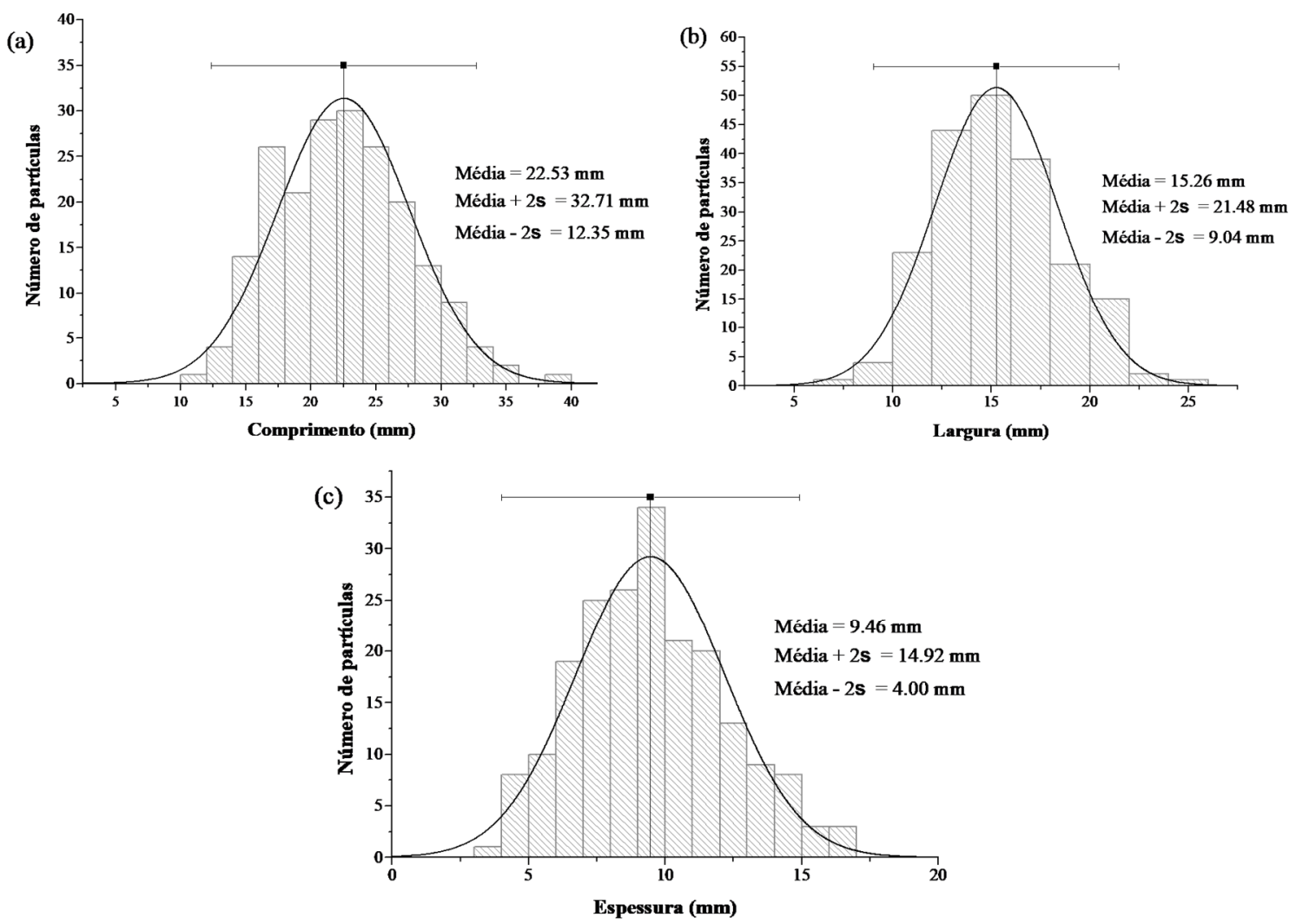

Figura 8. Histogramas com distribuição normal dos valores de (a) comprimento, (b) largura e (c) espessura das partículas

Tabela 3 - Valores finais de dimensões médias, em milímetros, relações entre dimensões e classificação de forma dos agregados

\begin{tabular}{llll|lll}
\hline & $\boldsymbol{a}$ & $\boldsymbol{b}$ & $\boldsymbol{c}$ & Relação & Valor & Classificação \\
\hline Média & 22,15 & 14,97 & 9,27 & $b / a$ & 0,68 & \\
Desvio & 4,62 & 2,83 & 2,50 & $c / b$ & 0,62 & \multirow{2}{*}{ Cúbica } \\
& & & & Índice de forma $=a / c$ & 2,39 & \\
\hline
\end{tabular}

\subsection{Validação do modelo numérico}

Os modelos numéricos foram desenvolvidos e calibrados conforme apresentou-se na Metodologia do presente trabalho, caracterizando tanto o comportamento viscoelástico da MAF, quanto o elástico do esqueleto sólido graúdo. Foram realizadas três simulações de ensaios de fluência estática e recuperação a partir do modelo constituído pelas duas fases (MAF + ESG). Cada simulação manteve as mesmas características da MAF, e foi variada, aleatoriamente pelo algoritmo de empacotamento, apenas a disposição dos agregados constituintes do ESG, fixando a forma e a distribuição granulométrica dos mesmos. Os resultados tiveram baixa dispersão das três curvas, com desvio padrão máximo de +/- 0,001 mm. A Figura 9 ilustra o comportamento da média das curvas numéricas em comparação com a curva experimental. Os resultados foram extremamente satisfatórios e demonstram que o modelo proposto é capaz de simular adequadamente o comportamento da amostra de CBUQ nas condições do ensaio de fluência. A introdução do ESG obviamente torna a mistura de CBUQ bem mais rígida que a MAF pura, o que pode ser observado pela redução dos deslocamentos ao final da fase de carregamento, que foi da ordem de $0,31 \mathrm{~mm}$ na MAF e 0,16 mm no CBUQ. 


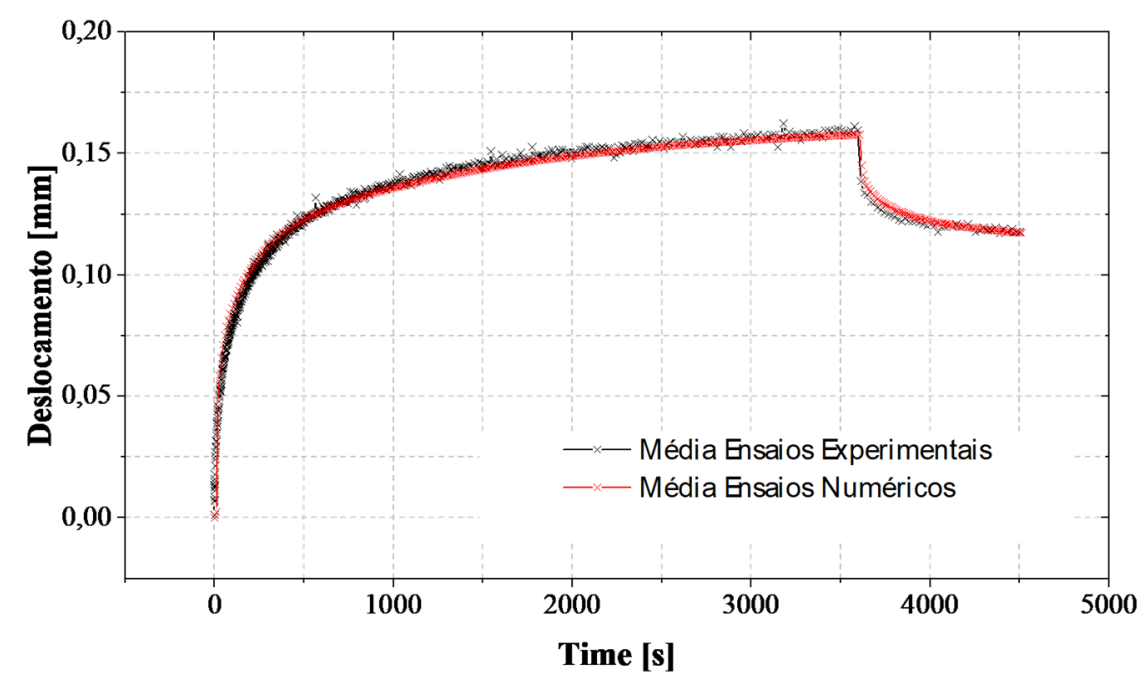

Figura 9. Comparação entre resultados experimental e numérico obtidos de ensaios de fluência estática

\section{CONCLUSÕES}

0 presente trabalho propõe uma metodologia de simplificação da geração de um modelo numérico que represente o comportamento de um corpo de prova de mistura asfáltica submetido a um ensaio de fluência estática. São produzidos agregados representativos por meio de um algoritmo de empacotamento de partículas tradicionalmente utilizado em modelagens de Elementos Discretos, de forma a reproduzirem a forma média e a distribuição granulométrica da composição real de uma mistura.

A pesquisa se propõe a suprir uma parte da modelagem numérica de misturas asfálticas, contribuindo para a geração de modelos mais realistas. Os autores buscam, por meio de análises experimentais simples, com paquímetro e ensaios de granulometria, fornecer parâmetros para a geração de um pacote de partículas que, incrustrados numa matriz asfáltica, compõem a mistura como um todo. 0 modelo proposto subsidia o estudo de comportamento mecânico da mistura sob diversas situações de carregamento, além de permitir a variação de características de forma, granulometria, e ocupação volumétrica dos agregados graúdos para efeitos comparativos.

Simplificações foram adotadas para compensar efeitos de plastificação não-contemplados, além de deslocamentos relativos. Para compensar o enrijecimento da mistura ao final do carregamento, foi adotado uma bimodularidade proporcional. 0 comportamento experimental pôde ser simulado, entretanto, para o descarregamento, a simulação restringe-se a um exemplo de uso do modelo proposto.

0 modelo geométrico apresentado se mostrou muito eficiente e, de posse de resultados experimentais de ensaios de fluência estática realizados em corpos de prova reais de CBUQ o mesmo foi validado. 0 método traz, então, significativos ganhos de tempo e custo para a realização numérica de ensaio de fluência estática em misturas asfálticas.

\section{AGRADECIMENTOS}

O presente trabalho foi realizado com apoio da Coordenação de Aperfeiçoamento de Pessoal de Nível Superior - Brasil (CAPES) - Código de Financiamento 001 e do INFRALAB/UnB. 


\section{REFERÊNCIAS}

ABNT (1983) NBR 7809: Agregado Graúdo - Determinação do índice de forma pelo método do paquímetro. Associação Brasileira De Normas Técnicas, Rio de Janeiro.

ABNT (1989) NBR 6954: lastro padrão: determinação da forma do material. Associação Brasileira De Normas Técnicas, Rio de Janeiro.

ABNT (2000) NBR NM 27: Agregados - Redução de amostra de campo para ensaios de laboratório. Associação Brasileira De Normas Técnicas, Rio de Janeiro.

Al-Rousan, T.; E. Masad; E. Tutumluer e T. Pan (2006) Evaluation of image analysis techniques for quantifying aggregate shape characteristics. Const. and Building Mat., v. 21, p. 978-990. DOI: 10.1016/j.conbuildmat.2006.03.005.

Aragão, F. T. S.; D. A. Hartmann; A. R. G. Pazos e Y. R. Kim (2015) Virtual fabrication and computational simulation of asphalt concrete microstructure. Int. J. Pavement Eng., v. 18(9), p. 859-870. DOI: 10.1080/10298436.2015.1066009.

Bagi, K. (2005) An algorithm to generate random dense arrangements for discrete element simulations of granular assemblies. Granul. Matter. v. 7, p. 31-43. DOI:10.1007/s10035-004-0187-5.

Bessa, I. S.; V.T.F. Castelo Branco; J. B. Soares e J. A. Nogueira Neto (2014) Aggregate Shape Properties and Their Influence on the Behavior of Hot-Mix Asphalt. Journal of Materials in Civil Engineering, v. 8, p. 04014212. DOI: 10.1061/(ASCE)MT.1943-5533.0001181.

Castillo, D.; S. Caro; M. Darabi e E. Masad (2017) Influence of aggregate morphology on the mechanical performance of asphalt mixtures. Road Materials and Pavement Design, v.19:4, p. 972-991, DOI: 10.1080/14680629.2017.1283357.

Dai, Q. (2011) Two- and three-dimensional micromechanical viscoelastic finite element modeling of stone-based materials with X-ray computed tomography images. Construction and Building Materials, v. 25, n. 2, p. 1102-1114. DOI: 10.1016/j.conbuildmat.2010.06.066.

Denby, E. F. A note on the interconversion of creep, relaxation and recovery. Rheologica Acta, v. 14, n. 7, p. 591-593, 1975. D0I: 10.1007/BF01520810.

DNER (1998) DNER-ME 083/98: Agregados - análise granulométrica. Departamento Nacional de Estradas e Rodagens, Rio de Janeiro.

DNIT (2004) DNIT 031/04-ES: pavimentos flexíveis: concreto asfáltico. Departamento Nacional De Infraestrutura De Transportes, Rio de Janeiro.

Duncan, J. M. e C.-Y. Chang (1970) Nonlinear analysis of stress and strain in soils. Journal of Soil Mechanics and Foundation Division, v. 96, n. 5, p. 1629-1653.

Farias, M. M.; E. M. Palmeira; I. A. Beja (2017) Agregados para a Construção Civil. Materiais de Construção Civil e Princípios de Ciência e Engenharia de Materiais. Ed. G.C. Isaia. 3aed. São Paulo, IBRACON, v. 2.

Farmer, I. W. (1968) Engineering behaviour of rocks. London, Chapman and Hall Ltd., 208p.

García, L. M. (2017) Influência da argamassa asfáltica na fluência de uma mistura idealizada. Tese (doutorado). Programa de Pós-Graduação em Geotecnia, Departamento de Engenharia Civil, FT, UnB. Brasília, DF. Disponível em: <https://repositorio.unb.br/handle/10482/24424> (acesso em 23/12/2019).

Huang, Y. H. (1993) Pavement analysis and design. Pearson Education, NJ, USA, 775 p.

Kim, Y. R. (2009) Modeling of Asphalt Concrete. ASCE Press, New York, USA, 460 p.

Morfa, C.R., L.A. Cortés, M.M. de Farias e I. P. P. Morales (2018) Comp. Part. Mech., v. 5: 319, n. 3, p. 319-334, DOI: https://doi.org/10.1007/s40571-017-0171-6.

Park, S. W. e Y. R. Kim (1999) Interconversion between Relaxation Modulus and Creep Compliance for Viscoelastic Solids. J. Mater. Civ. Eng., v. 11, p. 79-82. DOI: 10.1061/(ASCE)0899-1561(1999)11:1(76).

Pazos, A. G.; F. T. S. Aragão e L. M. G. Motta (2015) Efeitos de propriedades morfológicas de agregados no comportamento mecânico de misturas asfálticas. 44ạ Rapv - Reunião Anual De Pavimentação, Foz do Iguaçu.

Pérez Morales, I.; M. M. de Farias; R. R. Valera; C. M. Recarey e H. E. M. Carvajal (2016) Contributions to the generalization of advancing front particle packing algorithms. Int. J. Numer. Meth. Engng, v. 107, p. 993-1008. DOI: 10.1002/nme.5192.

Rocco, C. G. e Elices, M. (2009) Effect of aggregate shape on the mechanical properties of a simple concrete. Engineering Fracture Mechanics, v. 76, n. 2, p. 286-298. DOI: 10.1016/j.engfracmech.2008.10.010.

Rodrigues, I.A. (2018) Análise do Dano em Mistura de Agregados Finos (MAF). Dissertação (mestrado). Programa de Pós-Graduação em Geotecnia, Departamento de Engenharia Civil, FT, UnB. Brasília, DF. Disponível em: <https://repositorio.unb.br/handle/10482/33931> (acesso em 23/12/2019).

Valera, R. R.; I. Pérez Morales; S. Vanmaercke; C. M. Recarey; L. A. Cortés e H. D.-G. Casañas (2015) Modified algorithm for generating high volume fraction sphere packings. Computational Particle Mechanics, v. 2, n. 2, p. 161-172. Print ISSN 21964378. DOI: 10.1007/s40571-015-0045-8.

Xu, R.; X. H. Yang; A. Y. Yin; S. F. Yang e Y. Ye (2010) A three-dimensional aggregate generation and packing algorithm for modeling asphalt mixture with graded aggregates. J. of Mech., v. 26, n. 2, p. 165-171. DOI: 10.1017/S1727719100003026.

Zelelew, H. (2008). Simulation of the permanent deformation of asphalt concrete mixtures using discrete element method (DEM). Tese (doutorado). Washington State University, Washington, USA.

Zhou, C.; M. Zhang; Y. Li; J. Lu e J. Chen (2017) Influence of particle shape on aggregate mixture's performance: DEM results. Road Materials and Pavement Design, v. 1-15, DOI: 10.1080/14680629.2017.1396236 